SAND93-0704

Distribution

Unlimited Release

Category UC-705

Printed June 1993

\title{
NUCLEAR WEAPON RELIABILITY EVALUATION METHODOLOGY
}

\author{
Reliability Assessment Department, 0335 \\ Sandia National Laboratories \\ Albuquerque, New Mexico 87185 \\ Reliability \& Electrical Systems Department, 8116 \\ Sandia National Laboratories \\ Livermore, California 94551
}

Prepared by

Donald L. Wright

Reliability Assessment Department. 0335

Sandia National Laboratories

Albuquerque, New Mexico 87185

\begin{abstract}
This document provides an overview of those activities that are normally performed by Sandia National Laboratories to provide nuclear weapon reliability evaluations for the Department of Energy. These reliability evaluations are first provided as a prediction of the attainable stockpile reliability of a proposed weapon design. Stockpile reliability assessments are provided for each weapon type as the weapon is fielded and are continuously updated throughout the weapon stockpile life. The reliability predictions and assessments depend heavily on data from both laboratory simulation and actual flight tests. An important part of the methodology are the opportunities for review that occur throughout the entire process that assure a consistent approach and appropriate use of the data for reliability evaluation purposes.
\end{abstract}




\section{PREFACE}

This document presents an overview of the methodology used by Sandia National Laboratories (SNL) in performing reliability evaluations of nuclear weapons. As such, this document supersedes SAND79-0991, Reliability Analysis of Sandia Designed Nuclear Weapon Ordnance, John M. Wiesen, July 1979 (reprinted January 1983). The information presented has been extracted from a companion document, the Nuclear Weapon Reliability Evaluation Methodology Guide. This Guide documents the policies, practices and processes of SNL reliability evaluation organizations. The Guide is reviewed and revised periodically to reflect current practices and is maintained by SNL Reliability Assessment Department, 0335. For further information or detail concerning the implementation of the methodology described by this report, please contact:

Reliability Assessment Department, 0335

Sandia National Laboratories

P.O. Box 5800

Albuquerque, New Mexico 87185.

or

Reliability \& Electrical Systems Department, 8116

Sandia National Laboratories

P. O. Box 969

Livermore, California 94551 


\section{CONTENTS}

Page

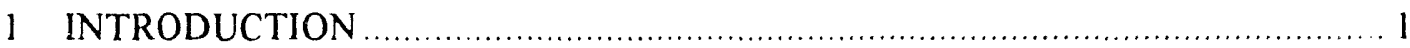

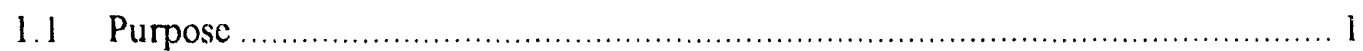

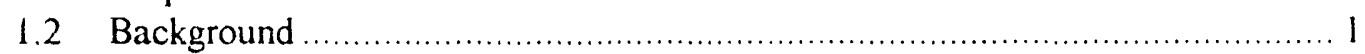

1.2.1 Definition of Nuclear Weapon Reliability ..................................... 1

1.2.2 Definition of Stockpile Life ....................................................... 2

1.2.3 Reliability or Probability Statements ............................................. 3

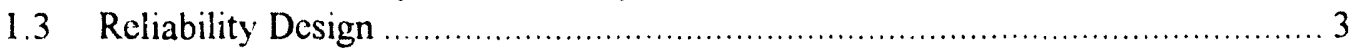

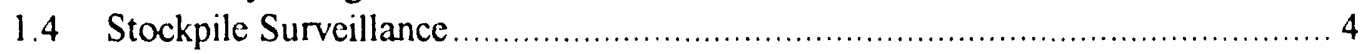

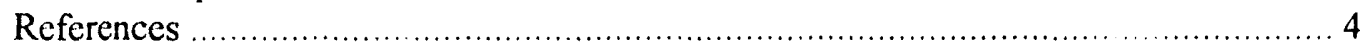

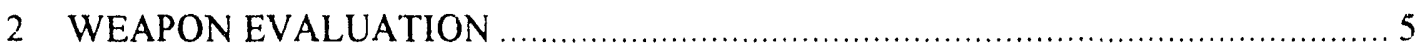

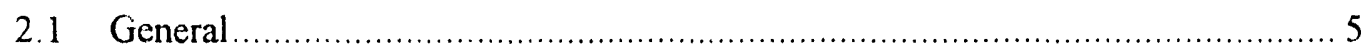

2.1.1 Modeling .............................................................................. 5

2.1.2 Prediction and Assessment Analyses ........................................ 5

2.1.3 Reliability Review Panel............................................................ 8

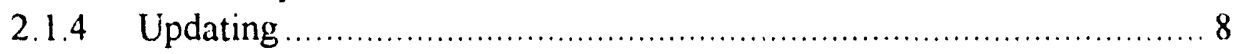

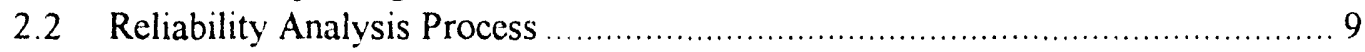

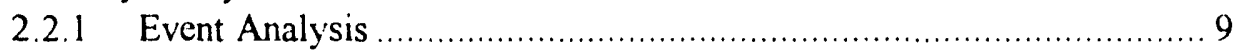

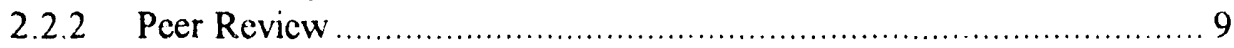

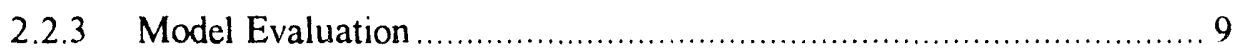

2.2.4 Analysis Documentation and Manager Review............................. 9

2.3 Summary of Reliability Activities ........................................................... 9

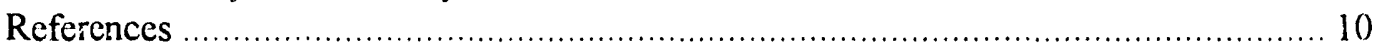

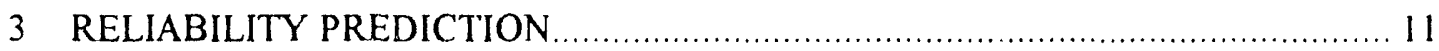

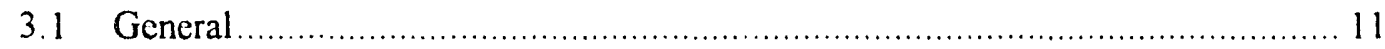

3.2 Reliability Prediction Methodology ...................................................... 11

3.3 Component Prediction Process ........................................................... 12

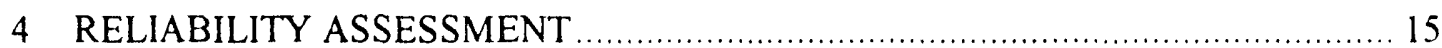

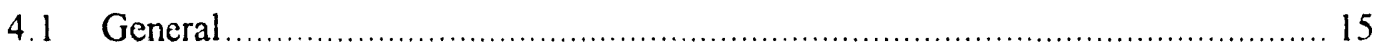

4.2 Component Assessment Methodology ....................................................... 15

4.3 Component Reliability Assessment Process .................................................. 16

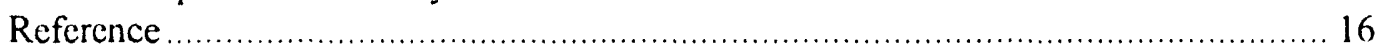




\section{FIGURES}

Page

Figure 1.1 Potential Modes of Behavior as Function Of Weapon Life ..........2

Figure 2.1 Weapon Reliabilıy Evaluation Process ................................... 6

Figure 2.2 Reliability Prediction/Assessment Analysis Process .................. 7

Figure 2.3 Block Diagram and Reliability Model ................................... 8

Figure 2.4 Reliability Activities ...................................................... 10

Figure 3.1 Reliability Prediction Methodology ..................................... 11

Figure 3.2 Component Reliability Prediction Process ............................... 13

Figure 4.1 Component Reliability Assessment Methodology ....................... 15

Figure 4.2 Component Reliability Assessment Process ........................... 17 


\section{NUCLEAR WEAPON RELIABILITY EVALUATION METHODOLOGY}

\section{1 - INTRODUCTION}

1.1 Purpose. Sandia National Laboratories (SNL) provides periodic review of all applicable test data and the evaluation of the reliability of active stockpile nuclear weapon systems for the U. S. Department of Energy (DOE). The purpose of this document is to describe the reliability analysis methodology for nuclear weapon ordnance as employed by SNL. The methodology presented is based upon a complete weapon development program as defined in Ref. 1.2. The methodology for an upgrade to an existing weapon or for a non-traditional development program is adapted from the methodology presented to provide the applicable reliability analysis elements. The methodology presented can also be modified to meet the needs of nonnuclear weapon analyses.

1.2 Background. Unless otherwise noted, weapon refers to that entity of a nuclear weapon for which the DOE has been assigned design and procurement responsibility. These entities are generally referred to either as warheads or bombs. For certain weapons in which the DOE portion is integrated with the Department of Defense (DoD) portion, SNL participates in joint DOE/DoD reliability evaluations and reports the results of these joint studies.

\subsubsection{Definition of Nuclear Weapon Reliabil-}

ity. Functional nuclear weapon reliability is defined as the probability that during the stockpile life of the weapon and over the envelope of normal environments defined in the
Stockpile-to-Target Sequence (STS), the desired nuclear yield at the target will be achicved.

The reliability requirements and specifications for nuclear weapons are contained in Military Characteristics (MCs) and Stockpile-to-Target Sequence (STS) documents (Ref. 1.3). These documents are provided by the DoD and define the required weapon function and the envelope of environmental conditions to which the weapon may $b c$ subjected in the normal course of stockpile storage and conflict usage. These documents alio specify certain requirements for the weapon in the event of or following exposure to "abnormal" or accident environments. It is assumed that weapon functionality is not assured during or following exposure to any environment beyond the normal environment envelope. Thus, the evaluation methodology described in this document assumes only "normal" environment situations.

A functional reliability requirement for differing delivery and/or firing options may be specified individually in the MCs. Cortim improper operations, such as higher-than-desired nuclear yield or premature nuclcar detonation may also have probability requirements of occurrence or non-occurrence specified. The functional reliability and premature probability requirements associated with certain use-control functions may also be specifid. Each of these requirements (both functional and premature) is evaluated using the methodology described in this document. 
1.2.2 Definition of Stucknile Life. For cvaluation purposes, the stockpile life of a weapon is assumed to include the most severe combination of dormant storage and delivery nomal environments speiified, including maximum dormant storage tine. There are several undesirable weapon behiviors that can occur during weapon stockpile life. Figure 1.1 illustrates the relationship of various behaviors in the weapon total mission ti ne domain, including domant stockpile storage Weapon success can oceur only in a small winc ow of the weapon total life time. The remaining time windows can have certain undesirable weapon behaviors that preclude success. 'The reliability of the weapon can be expressed as one minus the sum of the probabilitics of occurrence of these undesirable behaviors which are descritied below. The probability associated with each individual behavior is not analyzed separately', but becomes part of the overall weapon reliability evaluation. a. Premature. An unintended nuclear detonation that oceurs in the nomal enviromment prior to safe separation from the carricr. This is also a concern from the standpoint of nuclear safety along with detonation resulting from an accident enviromment. The normal environment premature behavior is included in the STS normal environment reliability cvaluation.

b. Abort. Cancellation of use of the weapon, after it is "committed" to the mission, due to evidence that it would result in a failure

c. Flare Dud. An carly nuclear detonation that results in reduced target damage, but is not hazardous to friendly forces.

d. Dud. The failure to provide the prescribed function at the preper time, given proper inputs at the time of relcase/launch or during flight.

Figure 1.1

POTENTIAL MODES OF BEHAVIOR AS FUNCTION OF WEAPON LIFE

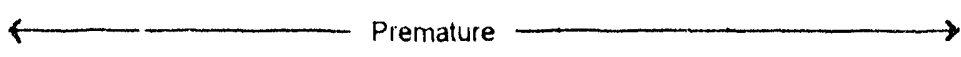

MODES
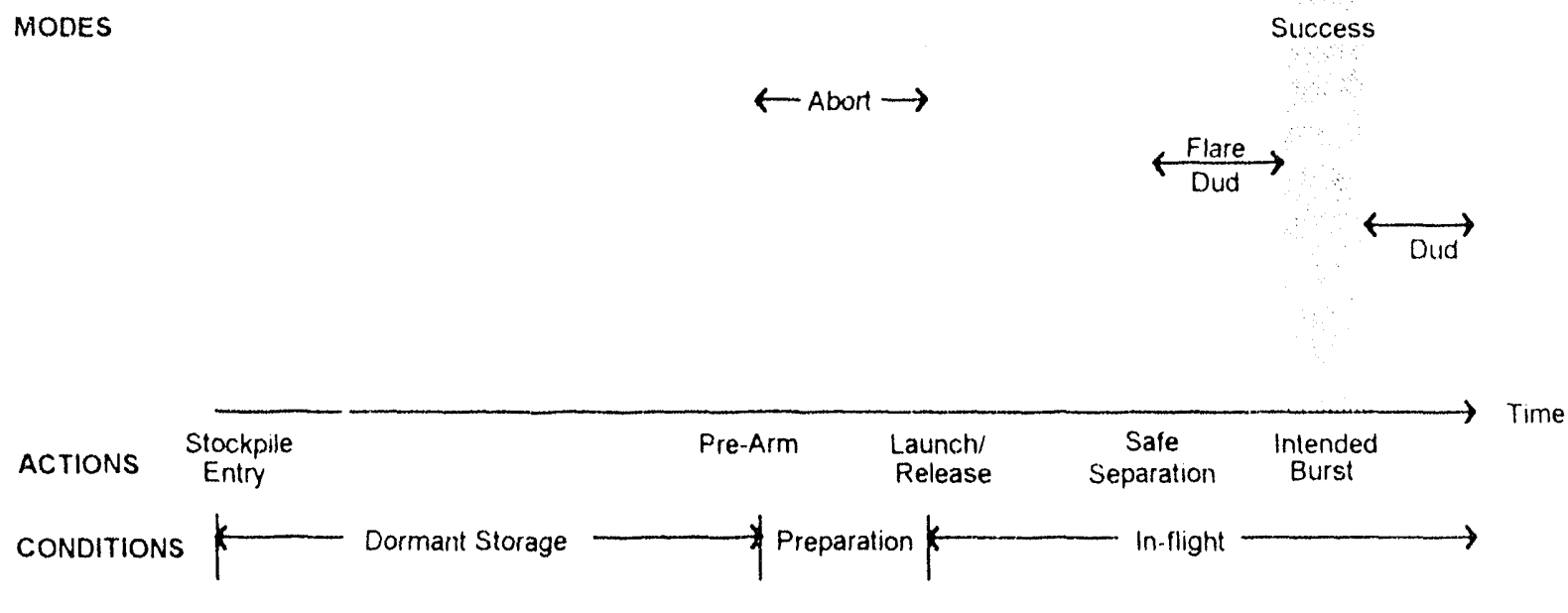

RELIABILITY $=1-$ UNRELIABILITY $=1-\{$ P(Premature $)+P($ Abort $)+P($ Flare Dud $)+P($ Dud $)\}$ 
1.2.3 Reliability or Probability Statements. Reliability or failure probability statements are sometimes referred to as either predictions or assessments. For the purpose of this document, predictions refer to statements that rely primarily on inference or extrapolation from similar if not directly applicable data. Assessments on the other hand are based on actual data or corroborating evidence available to assess the event or to support the prediction. The methodology employed for both the assessment and prediction analyses processes is essentially identical. Thus, the term "prediction" can generally be substituted whenever "assessment" is used to discuss the general methodology.

Reliability assessments for one-shot derices, such as nuclear weapons, must be based on statistical analysis of the results of tests of a sample of the stockpilc. Further..ore, the complexity and expense of many nuclear weapon sub-systems are such that large numbers of weapon tests are not feasible. Thus, sub-system test results must be combined with those from the weapon level.

The evaluation methodology employs mathematical models that reflect the probabilistic contribution of various system elements to the success (or failure) of the wcapon or sub-system. The elements are generally evaluated in terms of their failure probability and are typically reported with one significant non-zero digit. The individual probabilities are mathematically combined and the resultant weapon success probability or reliability is typically rounded to two decimal places (similar to the reliability requirement).

A reliability statement derived by the methodology presented in this document is based on the data currently available from various test programs and involves the mathematical combination of multiple probabilities. Both statistical and non-statistical types of inferences are involved in the evaluation process and with uncertaintics associated with each. While statistical uncertainties can be measured by statistical confidence statements, there is no method of measuring the non-statistical uncertaintics related to the diversity of the test programs involved. Because the overall uncertainty cannot be measured, confidence limits are not associated with the reliability statements based on this methodology:

Because of the wide spectrum of expected weapon deployment and potential use conditions, reliability assessments are generally not restricted to nominal conditions or any specific weapon stockpile age. Thus, unless otherwise stated, the reliability assessments represent realistic lower bound estimates that apply over the STS, and the assessments are assumed applicable throughout the remaining intended stockpile life. By this we mean that the reliability assessment applies to the extremes of the design environments and may be better at nominal or benign conditions. An example exception is if unanticipated agc degradation mechanisms are detected, the reliability statement will reflect a current "snapshot" of the stockpile reliability with additional notes that may project the expected rate of degradation.

1.3 Reliability Design. The design and development organizations are ultimately responsible for the reliability of the SNL designed portion of the nuclear weapon. Devcloping and providing weapon systems with high reliability involves many activities during design, development, production, and the stockpile period. The design organizations follow the principle that meeting the reliability requirements is one of their primary functions. Adherence to this principle provides the framework for the test and evaluation programs and prevents dependence on tenuous assumptions in the reliability analysis. Typically, the MCs provide guidance to the designers concerning the priority of reliability relative to competing characteristics such as safety, yield, operational simplicity, command and control, etc., as well as programmatic concerns such as cost and schedule. 
The desirable elements for attaining reliable product are:

a. Design to the worst case environmental conditions of the MCs and the STS and demonstrate the design capability by:

i. Thorough theoretical analysis that defines the response of the system and components under the extremes of environmental conditions,

ii. A variety of laboratory and flight tests to validate the theoretical analyses and to demonstrate performance to the $\mathrm{MC}$ requirements, and determine adequate design margin exists.

b. Establish controlled manufacturing processes to assure process variation and human errors do not degrade design intent.

c. Demonstrate continued production process performance through sample testing at the environmental extremes

d. Evaluate all failures for their cause and effect and implement appropriate corrective action.
1.4 Stockpile Surveillance. The SNL stockpile evaluation organization is responsible for the definition and execution of a New Material and Stockpile Evaluation Program (NMSEP) consisting of complementary system laboratory and flight tests (Refs. $1.4 \& 1.5$ ). This stockpile surveillance program is important for confirming the validity of development and product-acceptance test results. These tests provide for continuing surveillance of the stockpilc reliability and compatibility and allow for detection of unsuspected age degradation. The evaluation of all failures and anomalies for cause and effect provides the basis for corrective actions, modifications, and improvements necessary to maintain the stockpile. The results of this program are combined with the production data to provide a reliability assessment for cach nuclear weapon

\section{References}

1.1 DOE Order AL 56XC, AL Nuclear Weapons Stockpile Evaluation Program, June 1. 1990 .

\subsection{DOE Weapon Phases, EP401523.}

\subsection{Military Characteristics and Stockpile-to-} Target Sequence, EP401542.

1.4 Stockpile Evaluation Manual, Department 7260, SNL, February 1991.

1.5 New Material and Stockpile Systems Evaluation, EP401080 


\section{2 - WEAPON EVALUATION}

2.1 General. Figures 2.1 and 2.2 are flow diagrams that represent the weapon reliability evaluation process. For discussion purposes, the process is divided into sections on:
a. Modeling.
b. Prediction and assessment analyses.
c. Reliability Review Panel.
d. Updating.

2.1.1 Modeling. A System Reliability Engineer (SRE) is assigned weapon reliability evaluation responsibilities early in the weapon proposal or development phase. The SRE's first step is to represent the major functions of the weapon design in terms of expected and desired subsystem and component behaviors. This process is referred to as modeling and the usual result is a diagrammatic representation of the interrelating component bchaviors and a set of "reliability mathematical equations". Assumptions affect the accuracy of the mathematical equation and its evaluation. This is the first step of the process shown in Figure 2.1. Figure 2.3 gives an example block diagram model. Successful weapon function requires successful operation of all events listed. Some operations are represented by single blocks while others have two blocks - either of which can provide the needed operation. These functional relationships lead to a mathematical expression (see Figure 2.3) relating the weapon failure probability to component bchavior failure probabilities. Working with the SRE are Component Reliability Engineers (CREs) assigned to have and maintain in-depth knowledge of individual subsystems and components used in a variety of weapons. It is the responsibility of the CREs to monitor the design, development, production, and stockpile activities of their assigned sub-system and component product lines to support the SRE in developing, maintaining, and evaluating the weapon reliability model.

\subsubsection{Prediction and Assessment Analyses.}

The reliability model is an integral part of a series of analyses performed throughout the weapon development, production, and stockpile phases until the weapon system is retired from stockpile. These analyses are categorized as either reliability prediction or assessment analyses. The initial analysis is a prediction of the reliability assessment expected to be attainable by a weapon system that has completed the necessary development phases and production acceptance testing. The reliability prediction analysis results are used to compare competing design architectures and for allocating subsystem or component reliability design goals. Prediction analyses are used until sufficient test data are available that represent stockpile hardware. This generally occurs about the time the weapon cnters the stockpile at which time the analyses are referred to as assessments. The distinction between a prediction analysis and an assessment analysis is based primarily on the types of data used to derive or support the event probability values. Obviously, if the weapon does not yet exist as an entity, the resulting analysis is a prediction. As more data directly associated with the weapon use and configuration are accumulated, the analysis can be considered as an assussment of the stockpiled weapon. Stockpile entry is generally used to define assessment analyses. This is indicated by the top-most diamond-shaped decision block in Figure 2.1. The process for both weapon prediction and weapon assessment analyses is summarized in Figure 2.2 and is discussed in Section 2.2 (Reliability Analysis Process). 


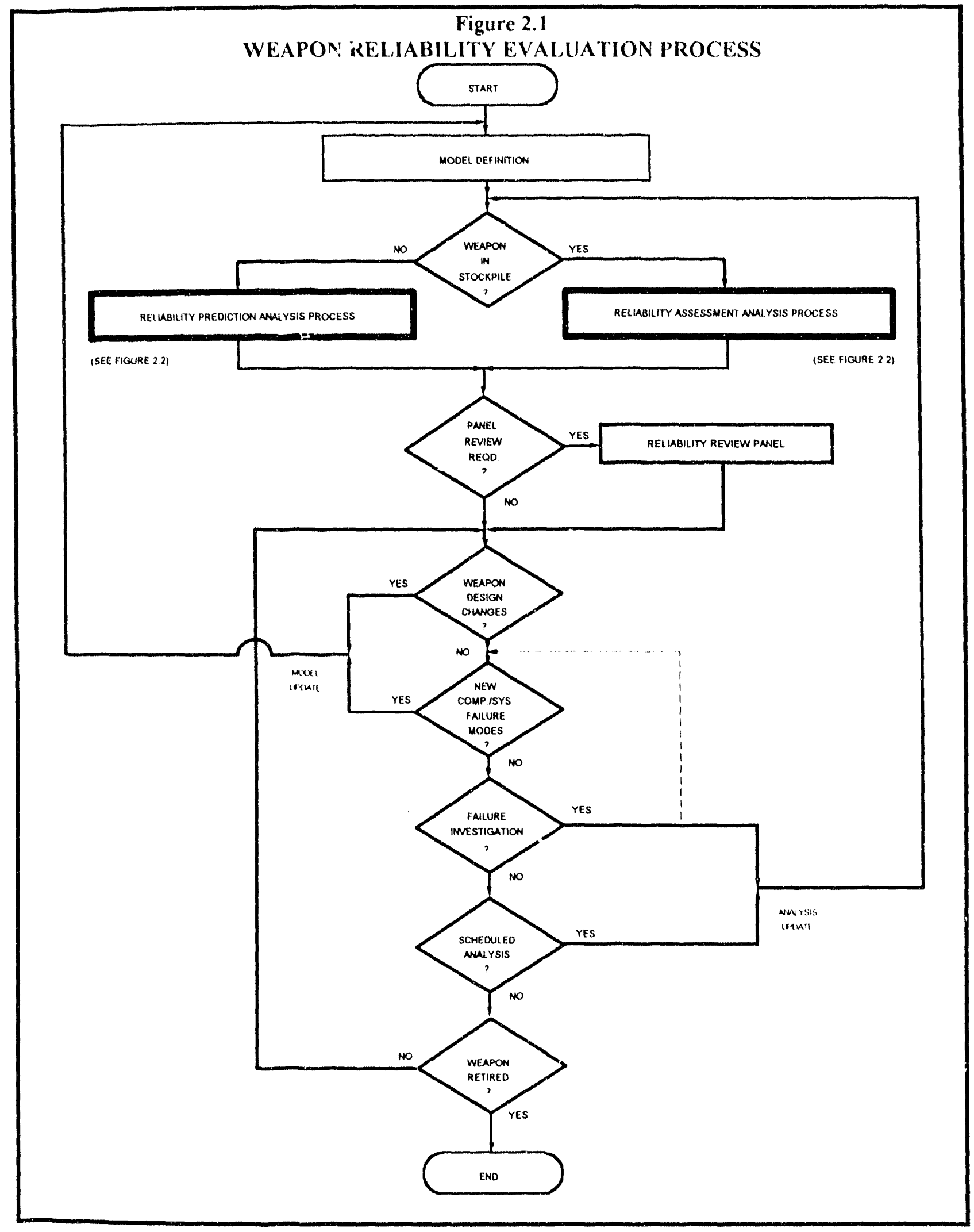


Figure 2.2

RELIABILITY PREDICTION/ASSESSMENT ANALYSIS PROCESS

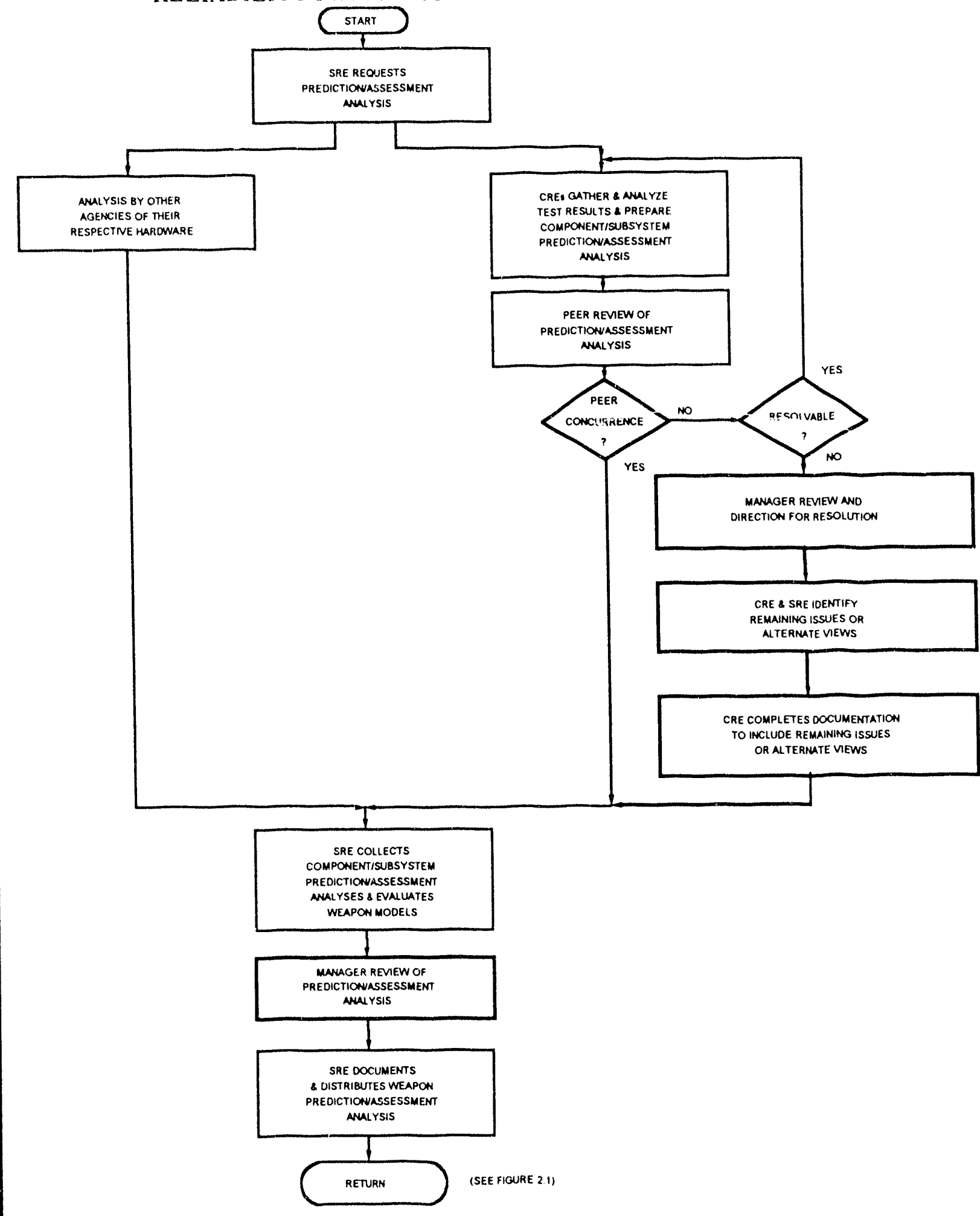




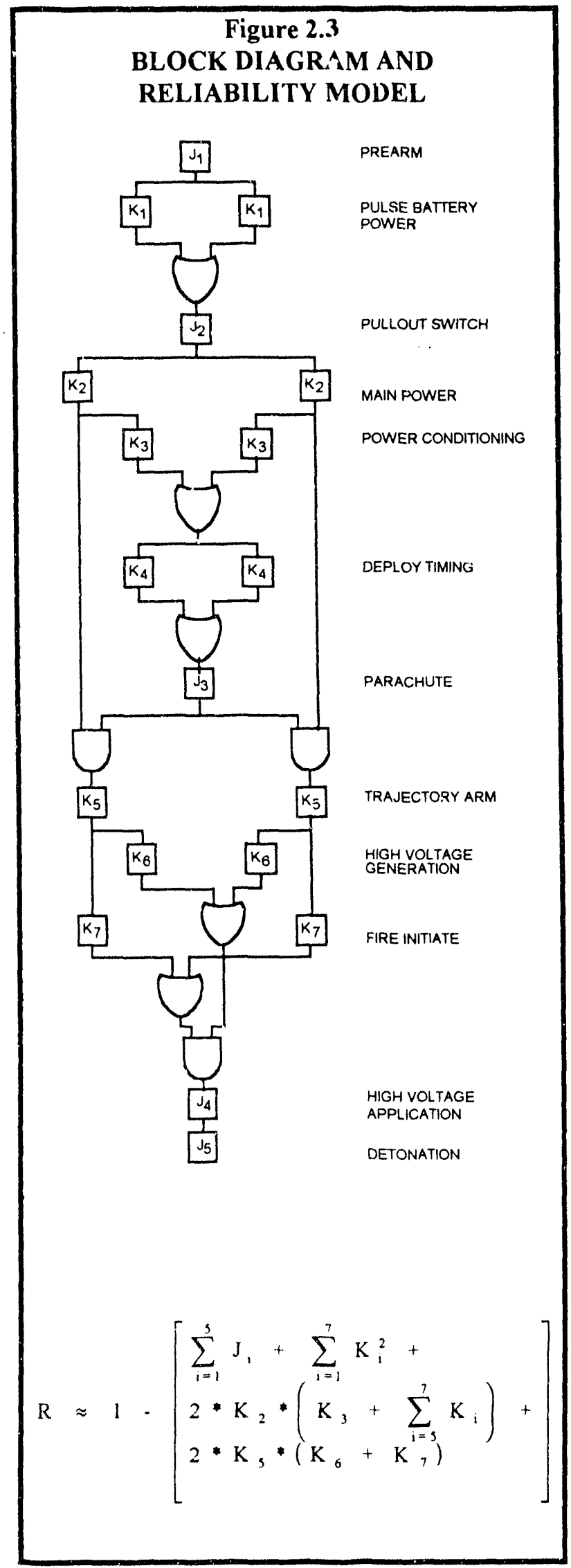

2.1.3 Reliability Review Panel. A review process consisting of a Reliability Revicw Panel (RRP) provides peer review of reliability activities associated with specific weapon programs (see Figure 2.1). Through this process the reliability activities are reviewed for completeness and consistency. The review pancl activities are accomplished in a number of different sessions that are related to specific nuclear weapon programmatic milestones (see Figure 2.4). The issues reviewed throughout this process include, but are not limited to:

a. Mathematical equation representation of weapon functions.

b. Failure exicnt descriptions.

c. Event prediction rationale.

d. Adequacy of data sources for assessment purposes.

e. Interpretation of obscrved failures.

2.1.4 Updating. The process flow chart of Figure 2.1 includes a number of decision blocks (shown as diamonds) that provide means for the continual refinement of both the model and the analytical evaluation throughout the weapon design, development, production, and stockpile life. The model is revised as appropriate when design changes are implemented or as additional failure modes are revealed. These can occur as the weapon design evolves during development or be the result of modification or retrofit during the weapon production or stockpile phases. Another stimulus for update is the discovery, investigation, and assignment of failure to an observed test anomaly. The potential reliability effect of every obscrved failure is evaluated. The investigation may reveal a new failure mode that needs to be defined as an event and included in the model. This action is shown by the dashed line in Figure 2.1 and results in a revision of the model and an update of the analysis. 
A scheduled analysis is also a stimulus for update, as shown in Figure 2.1. These may be prediction analyses to support various development activities or assessments of the stockpiled weapon. Reassessments are performed periodically after a weapon enters the stockpile and are referred to as updates in that any appropriate new data are included with the existing data to support the assessment. Typically, these types of reassessments are scheduled yearly while a weapon is in production, and then biennially until the weapon is retired from the stockpile. Supplying inputs for the semi-annual DOE Weapons Reliability Report are also scheduled activities (Ref. 2.1) as are analyses to support joint Department of Defense (DoD) and DOE evaluation activities.

The analysis update process described above provides a continuous means of adjusting reliability assessments that may be high (i.e., by including new failures or failure modes when they are observed), and a periodic means of correcting reliability assessments that may be low (i.e., by the addition of recent successes).

\subsection{Reliability Analysis Process. The re-} liability prediction/assessment analysis process shown in Figure 2.2 is initiated by rcquest of the SRE to the appropriate CREs (or other agencies) for prediction/assessment update of component events. The elements of this process are discussed in the following sections.

2.2.1 Event Analysis. The CREs gather and analyze test results preparing an event prediction/assessment analysis for each of the defined events in the mathematical equation. These analyses are documented in reports, usually by component or sub-system, and may be applicable to more than one configuration of a weapon family (referred to as Mods). The event prediction and assessment processes are described in Sections 3 and 4, respectively.
2.2.2 Peer Review. Each component or subsystem event prediction/assessment report is reviewed by another reliability engineer who is familiar with either the component or the weapon usage. This peer review is intended to assure consistent and supportable data usage and rationale. In the instance that peer review concurrence is not attainable, a management review and resolution process is implemented. Documentation of issues and alternate views that arise from this review process are included in the event assessment report by the CRE.

2.2.3 Model Evaluation. The SRE collects the individual prediction/assessment analyses and uses these probabilities to evaluate the weapon reliability using the mathematical equation.

2.2.4 Analysis Documentation and Manager Review. The SRE is responsible for documenting the weapon prediction or assessment analysis. The weapon reliability analysis is reviewed by the SRE's Department Manager before being published. The purpose of this review and approval step is to assure the consistency and accuracy of the analysis and the documentation.

2.3 Summary of Reliability Activities. Figure 2.4 summarizes the key weapon reliability activities relative to the DOE weapon development process. The weapon development process is defined in Ref. 2.2. The development of the reliability mathematical equation and the initial reliability predictions may begin in Phase 1 as shown by the dotted line. However, this must be completed early in Phase 3 in order to support the component allocation and prediction requirement. The refinement and update of the prediction and model continue throughout the development phases along with the evaluation of test anomalies. The initial weapon assessment is generally required late in Phase 5 as weapon production is entering stockpile. Periodic assessment updates and continuous evaluation of both production and stockpile surveillance test anomalies continue until the weapon is retired from the active stockpile. 


\section{References}

2.1 DOE Order AL 56XC, AL Nuclear Weap-

2.2 DOE Weapon Program Phases, EP401523. ons Stockpile Evaluation Program, June 1, 1990.

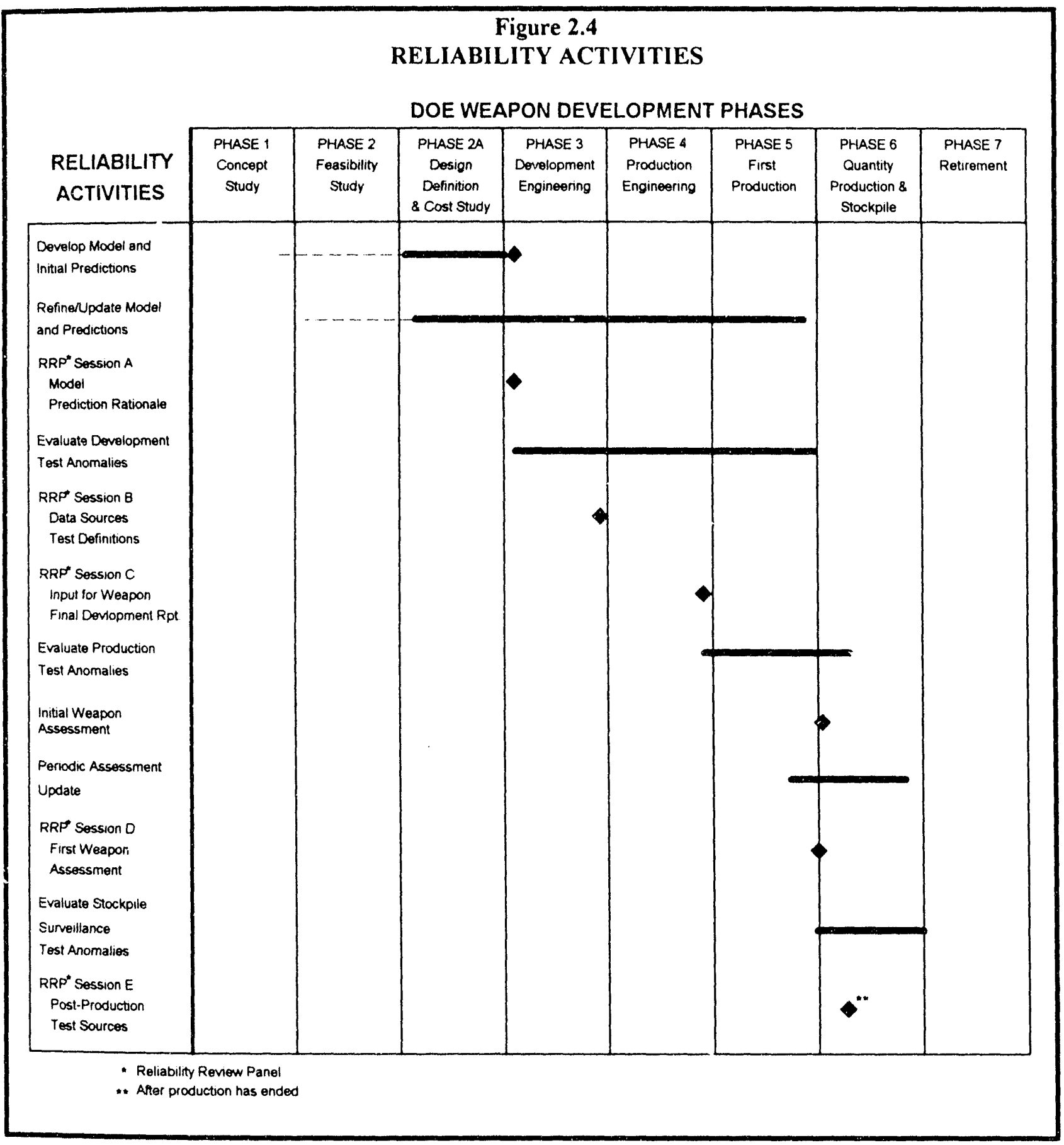




\section{3 - RELIABILITY PREDICTION}

3.1 General. Reliability predictions are preliminary estimates performed to provide visibility for both the reliability that may be achieved and the potential of alternate designs. Event predictions and assessments are very similar in that they are both data-driven estimates of event probabilities. They differ in the data sources and amount of data available for each. Predictions are initial estimates of event probabilities generally derived from historical data and experience with similar components or sub-systems. This history is used by means of extrapolation to obtain an event probability estimate for a newly specified weapon application. These predictions are the best event probability estimates available until additional data are generated to refute or to corroborate them.

3.2 Reliability Prediction Methodology. Figure 3.1 illustrates the prediction methodology in relation to the weapon definition and design phases. The weapon design or architecture is based on requirements from the Military Characteristics (MC) and Stockpile-to-Target Sequence (STS) documents provided by the

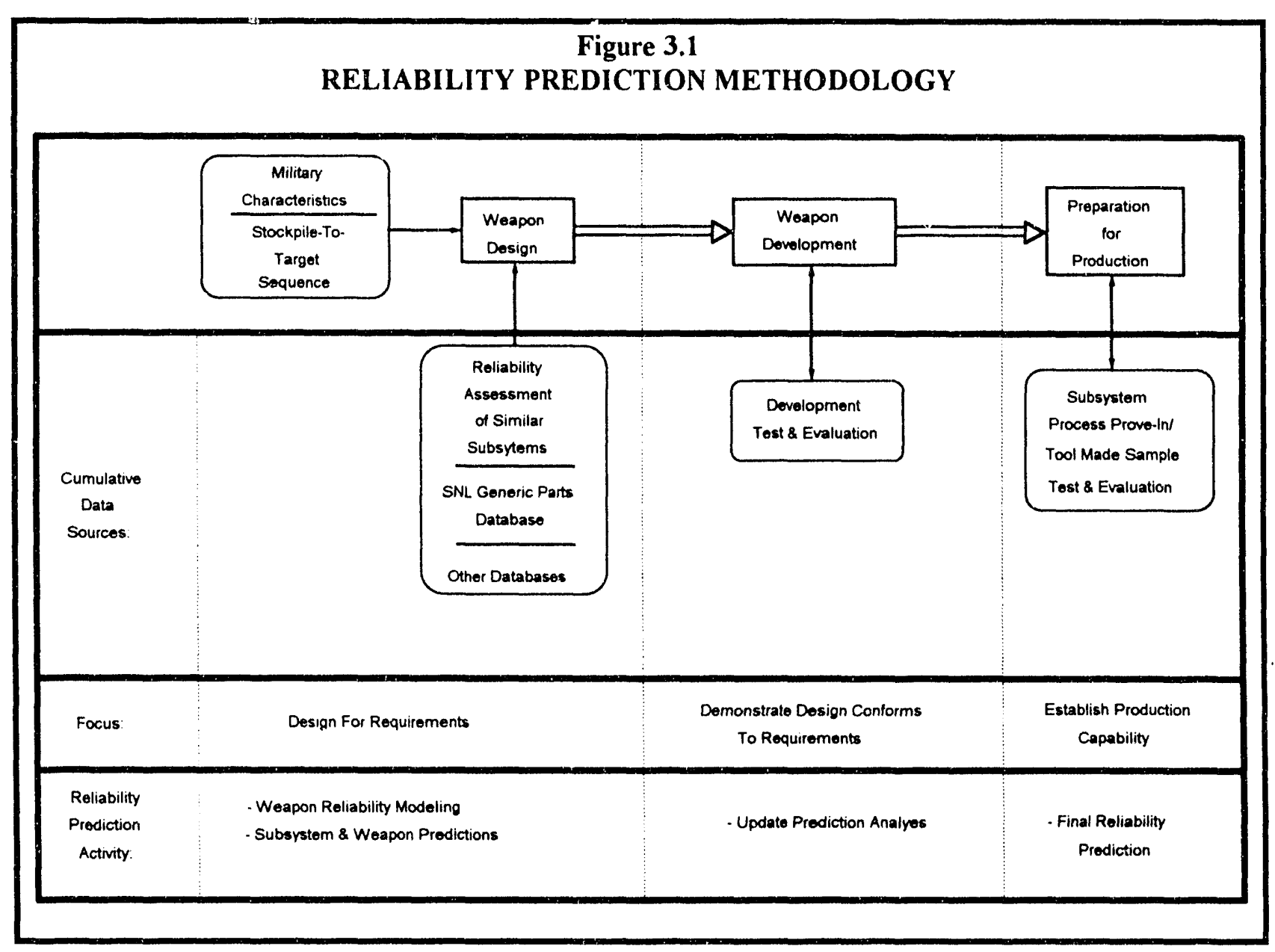


Department of Defense (DoD). These weapon requirements are translated into sub-system requirements such that the required system functions are achieved. The initial reliability predictions for the sub-systems may cause further development of the weapon architecture in order to achieve the weapon design requirements. These predictions are primarily based on historical assessments of similar sub-systems. Other databases and sources of data are also employed as needed. The process of deriving an individual component prediction is discussed in Section 3.3. As the weapon development program progresses, development test results are compared with the initial predictions which may cause adjustments to the predictions. Significantly more data become available for further comparisons as the sub-systems are prepared for War Reserve (WR) production. These data provide a final confirmation of the prediction validity.

\subsection{Component Prediction Process.}

Component reliability prediction is an essential sub-process of the nuclear weapon reliability prediction methodology. Figure 3.2 presents the steps of the reliability prediction process summarized below.

a. Understand proposed design and application.

b. Search for similar designs that can provide a basis for predicting the final capability of the proposed design.

i. If a similar design exists, consider effect of differences between proposed design and application with the reference unit.

ii. If no similar design exists, combine elemental part failure mode probabilities so as to form a prediction for the assembly.

c. Document prediction rationale. 


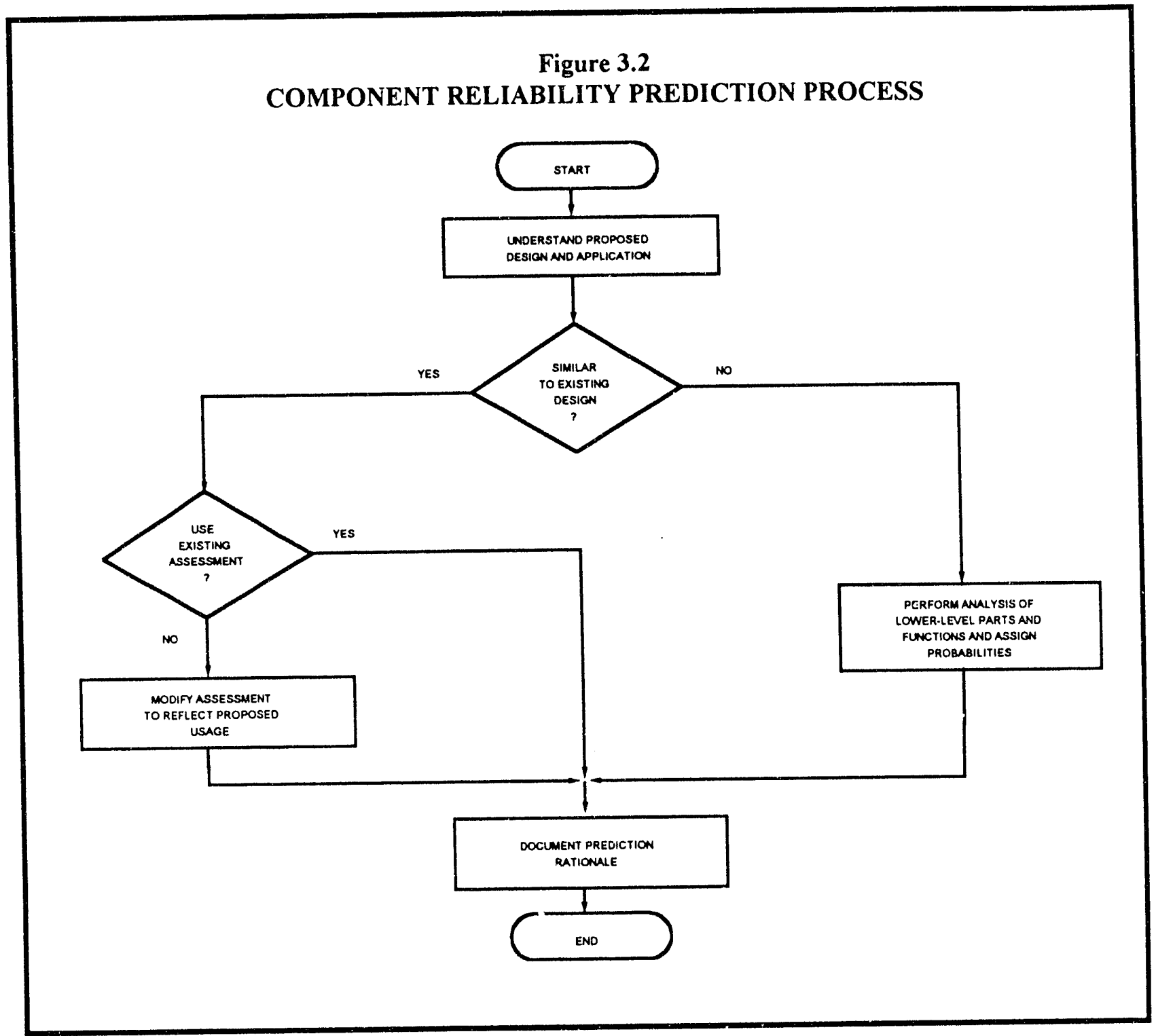


THIS PAGE INTENTIONALLY LEFT BLANK 


\section{4 - RELIABILITY ASSESSMENT}

4.1 General. Reliability assessments are derived for individual behaviors or functions of components or sub-systems. These behaviors or functions are referred to as events. The assigned event probabilities are used in the derivation of weapon-level probabilities through the use of mathematical equations. The events must be precisely described and, of course, must be assessable. Assessability means that applicable tests can be and are conducted so as to detect event occurrence and thus allow the proper identification of the outcome of each trial.
4.2 Component Assessment Methodology. The component event assessment methodology is based on a complementary set of test programs from which test data are derived for assessment purposes. Figure 4.1 illustrates this methodology and the relationships of the primary test programs for each component or sub-system.

The production process involves many operations and generally a large amount of in-process and $100 \%$ acceptance testing is performed. However, these tests are generally not considered

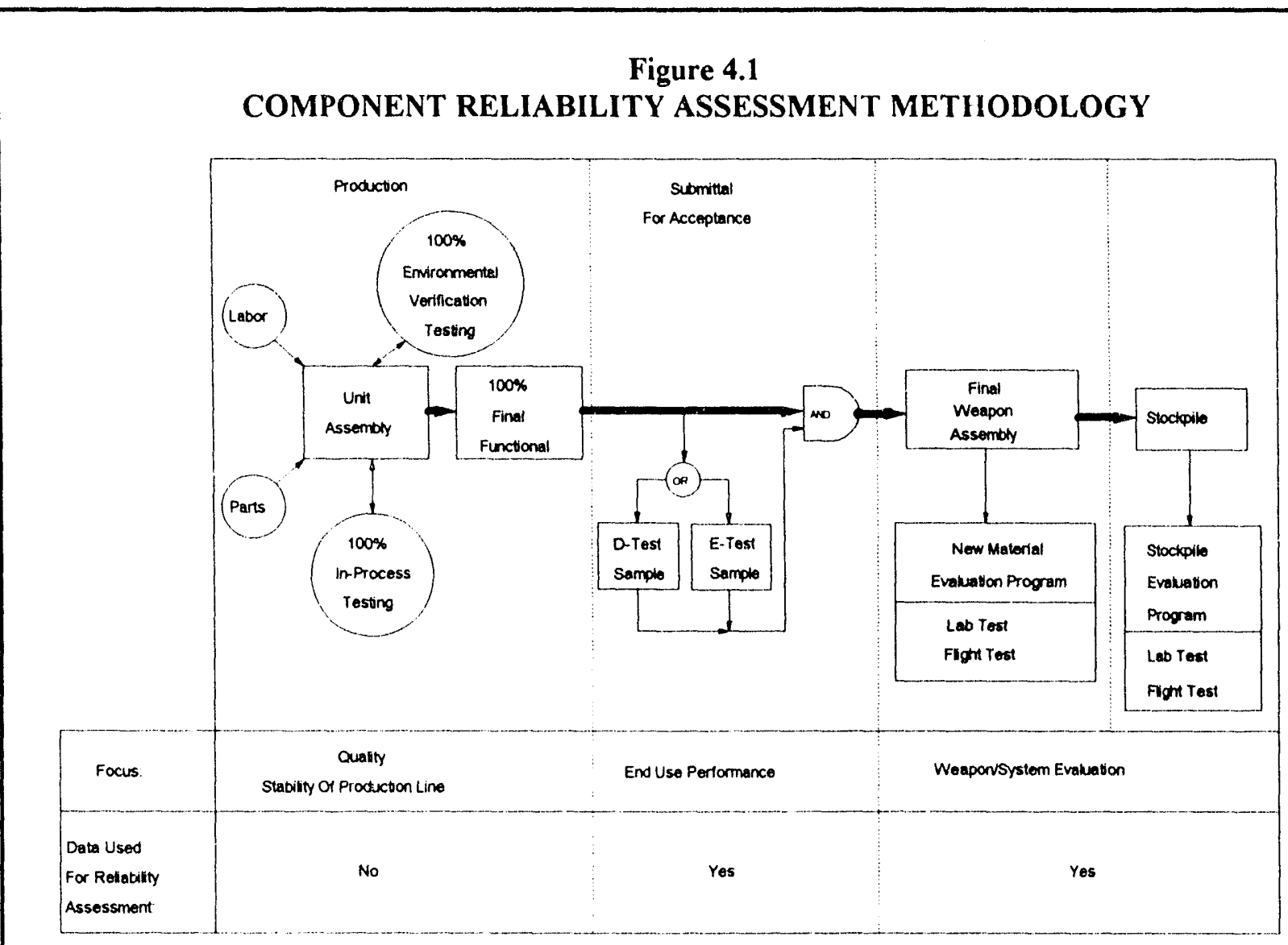


useful for event assessment purposes; rather, they provide means of assuring the qirality of the product and the stability of the production processes.

Submittal for product acceptance requires the selection and test of random samples from the production quantity. The results of these tests, designed to subject the units to use conditions and to meet use performance requirements, are used to determine continued acceptance of the product. Sample testing considered to be degrading or destructive is laheled D-Test. Non-degrading sample testing is labeled E-Test. This is a standard data source for assessment purposes. The product may become a part of a next assembiy that undergoes another similar production and submittal process.

Final weapon assemblies are randomly sampled as part of the New Material and Stockpile Evaluation Program (NMSEP). The goal of this program is to discover significant failure mechanisms associated with operational function, use control, and safety features of a weapon, soon enough for corrective action implementation to avert serious consequences (Ref. 4.1). The program also establishes a baseline for comparisons with later test results to detect degradation in the stockpile. This program provides weapon-level data early in the weapon stockpile cycle and is one of the standard data sources for reliability assessment purposes.

The NMSEP also provides for randomly sampled weapons from the stockpile that are converted to test units for subsequent operational flight tests or laboratory simulation tests. These are units that have been subjected to normal stockpile handling and dormant storage. This program is a standard data source and provides a continuing means of evaluating the stockpile for failure mechanisms induced during design, production, field handling, and by long-term dormant storage.

Non-standard data sources may be used if they are judged to be applicable and the standard sources are not available or sufficient.

\subsection{Component Reliability Assessment Proc-}

ess. Component event assessment is an important step in the nuclear weapon reliability assessment methodology. The applicability of both standard and non-standard data sources is determined by the ability of the test program to provide data that are representative of critical use and environmental condition and the ability to detect critical failure mechanisms. Determining the applicability of the data may involve both statistical methodology and engineering judgment. Figure 4.2 presents the steps of the component reliability assessment process summarized below.
a. Gather Data.
b. Determine Applicability.
c. Combine Data.
e. Assess and Document.

\section{Reference}
4.1 Stockpile Evaluation Manual, Department 7260, SNL, February 1991.


Figure 4.2

COMPONENT RELIABILITY ASSESSMENT PROCESS

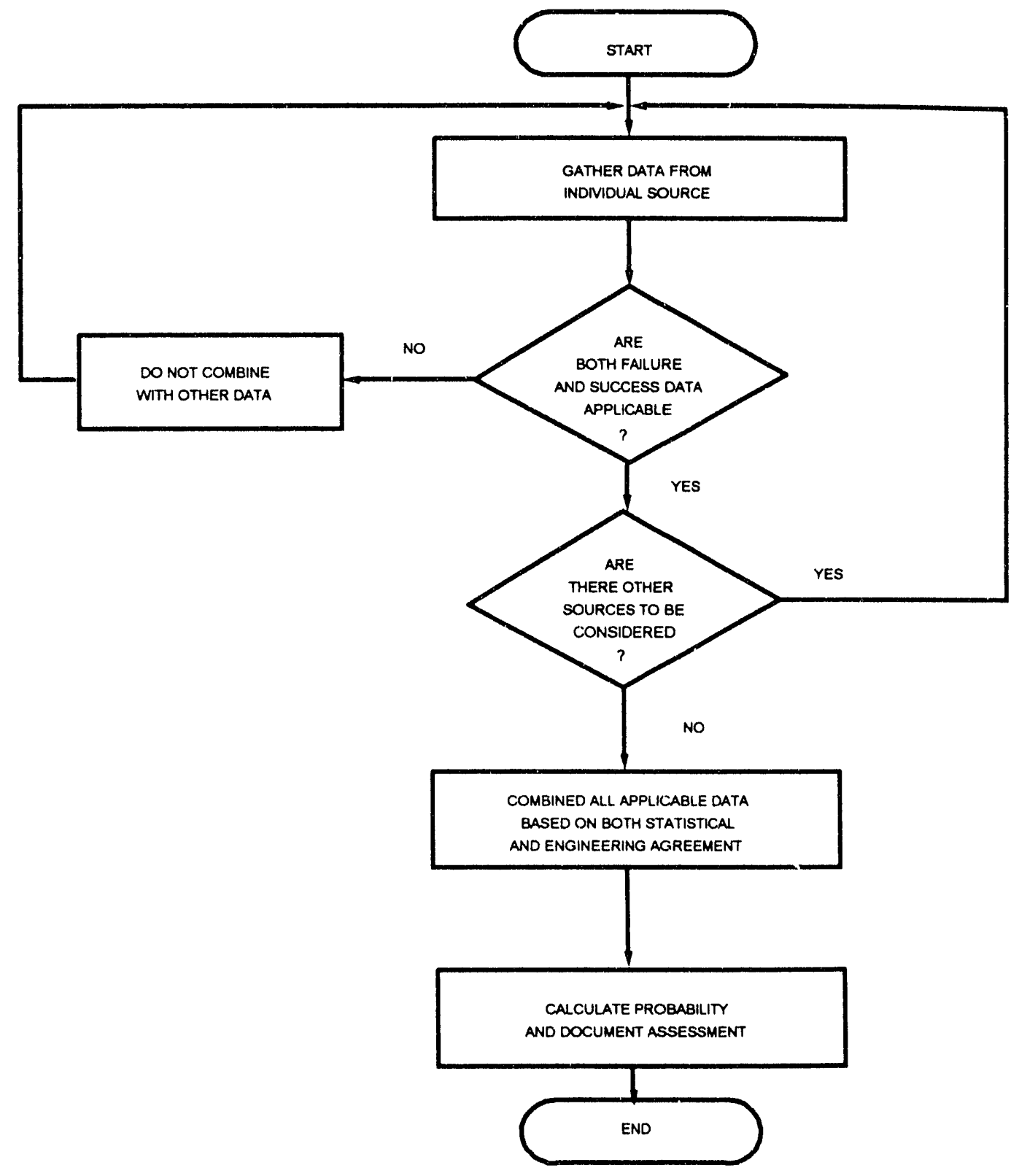




\section{DISTRIBUTION:}

3 U.S. Department of Energy

M/S AD-622.1

ATTN: Rear Adm. W. G. Ellis

P.O. Box A

Germantown, MD 20874

15 U.S. Department of Energy Albuquerque Operations Office ATTN: B. G. Twining, OOM

S. J. Guidice, OOW

A. E. Whiteman, WQD

R. Levine, WQD (7 cys)

H. T. Season, Jr., WPD (2 cys)

M. J. Eckart, QOB (2 cys)

L. J. Riedl, Jr., S\&W

1 U.S. Department of Energy

Amarillo Area Office

ATTN: P. M. Ramey, Area Manager

P.O. Box 30030

Amarillo, TX 79120

1 U.S. Department of Energy

Dayton Area Office

ATTN: L. D. Kirkman, Actg. Area Manager

P.O. Box 66

Miamisburg, OH 45342

1 U.S. Department of Energy

Kansas City Area Office

Supervisor, Document Control

ATTN: E. W. Bean, Area Manager

P.O. Box 419159

Kansas City, MO 64141-6159

1 U.S. Department of Energy

Pinellas Area Office

ATTN: R. E. Glass, Area Manager

P.O. Box 2900

Largo, FL 34694
I U.S. Department of Energy

Rocky Flats Office

ATTN: A. H. Pauole, Actg. Manager

P.O. Box 928

Golden, CO 80402-0928

1 U. S. Department of Energy

Technical Information

ATTN: Weapon Data Index

P.O. Box 62

Oak Ridge, TN 37831

1 U.S. Department of Energy

Oak Ridge Opcrations Office

ATTN: J. La Grone, Manager

P.O. Box 2001

Oak Ridge, TN 37831-8764

1 U.S. Department of Energy

Savannah River Operations Office

ATTN: M. P. Fiori, Manager

P.O. Box A

Aiken, SC 29802

1 Office of the Assistant to the Secretary of

Defense (Atomic Energy)

Room 3E1074, The Pentagon

Washington, DC 20301-3050

1 Nuclear Weapons Council

Office of the Assistant to the Secretary of

Defense (Atomic Energy)

ATTN: G. L. Cliff, NWC Staff

Room 3E1074, The Pentagon

Washington, D.C. 20301-3050

2 Director

Defense Nuclear Agency

ATTN: SSAB

NOSM

6801 Telegraph Road

Alexandria, VA 22310-3398 
1 Field Command, Defense Nuclear Agency/FCSAC

ATTN: FCPSQ

Kirtland AFB, NM 87115-5000

1 Organization of the Joint Chiefs of Staff Nuclear and Chemical Division, J-5, RF\&D Branch

ATTN: Nuclear Stockpile Branch

The Pentagon

Washington, DC 20318-5000

1 Commander

Naval Sea Systems Command

Dept. of the Navy

Nuclear Weapons Div. (SEA-6631)

Washington, DC 20362-5101

1 Commander

Naval Sea Systems Command

Theater Nuclear Warfare Program

ATTN: PMS-423

Washington, DC 20362-5101

1 Director, Strategic Systems Programs

Office/SP-272

ATTN: B. Hannah

1931 Jefferson David Hwy.

Bldg. CM\#3

Arlington, VA 22202

1 Commanding Officer

Naval Warfare Assessment Center

ATTN: $34 \mathrm{~W}$

Corona. CA 91720-5000

2 Commanding Officer

Naval Weapons Station

ATTN: Code 53

Seal Beach, CA 90740-5000

1 AF Dir. of Plans/DCS/OP\&R

HQ USAF/XOO

ATTN: XOOSS

Washington, D.C. 20330-5054
2 Commander

USSTRATCOM

ATTN: J541

J5243

901 SAC BLVD.

Suite 2E8

Offut AFB, NE 68113-6500

1 LGW

HQ ACC/LG

Bldg. 681

Langley AFB, VA 23665-5541

1 San Antonio ALC/SWM

ATTN: Margarita Perez/Charles Harvey/ Jesse E. Castoreno/Elisao Garza

Kelly AFB, TX 78241-5000

1 AFLC Nuclear Support Office/SWN ATTN: Maj. Ben Woosley/Diana F. Dow Kirtland AFB, NM 87117-5000

1 PL/SUL

Kirtland AFB, NM 87117-6008

5 Los Alamos National Laboratory

ATTN: G. G. Hill, WX-DO

H. L. Flaugh, WX-DO

T. T. Scolman, F-670

T. D. Robinson, WX-5

J. Barker, M7

P.O. Box 1663

Los Alamos, NM 87545

7 University of California

Lawrence Livermore National Laboratory

ATTN: W. H. Hubbell, L125

D. A. Nowak, L13

R. E. Clough, L125

M. R. Anastasio, L35

J. L. Robbins, L125

W. G. Moen, L 125

P.O. Box 808

Livermore, CA 94550 
7 AlliedSignal, Inc.

Kansas City Division

ATTN: J. Templin, D/400

D. R. Wachter, D/400

I. G. Schust, D/414

D. L. Cheray, D/453

J. V. Grice, D/454

J. J. Wyckoff, D/454

P.O. Box 419159

Kansas City, MO 64141-6159

1 Mason \& Hanger-Silas Mason Co., Inc.

Pantex Plant

ATTN: J. C. Drummond

P.O. Box 30020

Amarillo, TX 79177

1 EG\&G

Mound Applied Technologies, Inc.

ATTN: R. A. Fischbein

P.O. Box 3000

Miamisburg, $\mathrm{OH} 45343-3000$

1 Martin Marietta Energy Systems, Inc.

Y-12 I'lant Records Dept., Bldg. 9711-5

ATTN: H. D. Bewley

P.O. Box 2009

Oak Ridge, TN 37831-8169

1 EG\&G Rocky Flats, Inc.

Rocky Flats Plant

ATTN: J. O. Zane

P.O. Box 464

Golden, CO 80402-0464

1 Martin Marietta Specialty Components, Inc.

ATTN: W. F. Ierna

P.O. Box 2908

pLargo, FL 34649-2908

1 Westinghouse Savannah River Co.

Savannah River Site

ATTN: D. L. Hayes

Aiken, SC 29808
11 A. Narath

ATTN: 20 O. E. Jones

1300

1302

1303

1323

1326

1333

$1 \quad 334$

$50 \quad 335$

1336

1361

1363

1364

12000

12200

12203

12276

12300

12314

$1 \quad 2334$

$1 \quad 2337$

12341

12343

12400

12500

12512

12513

12522

12523

12561

12571

$125 \%$

12600

12700

14000

4111

14111

14523

15000

15100

15111

15115

15151
R. L. Schwoebel

G. T. Merren

J. L. Duncan

R. G. Easterling

M. A. Blackledge

R. E. Smith

G. C. Novotny

J. M. Sjulin

E. M. Austin

R. F. Hahn

J. N. Middleton

O. R. Hernandez

H. W. Schmitt

R. E. Bair

T. A. Dellin

W. M. Miller

R. D. Andreas

M. J. Mundt

G. M. Heck

W. D. Williams

T. J. Ferguson

W. H. Schaedia

J. Q. Searcy

G. N. Beeler

J. G. Harlan

F. H. Braaten, Jr., Actg.

K. R. Grothaus

R. B. Diegle

F. M. Bacon

T. J. Williams

J. A. Wilder

J. H. Stichman

R. A. Daviü

G. P. Robinson

ATTN: 4100 G. R. Otey

G. S. Brown

F. W. Müller

H. L. Floyd

R. L. Hagengruber

W. C. Nickell

W. J. Patterson

J. O. Harrison

D. D. Tipton 
15153 F. F. Dean

15161 J. A. Anderson

15167 J. K. Shane

ATIN: D. K. Duffy

AWEG, UK

$\begin{array}{lll}1 & 5200 & \text { E. E. Ives } \\ 1 & 5300 & \text { J. B. Wright } \\ 1 & 5354 & \text { E. T. Cull, Jr. } \\ 1 & 5362 & \text { C. A. Pura } \\ 1 & 5363 & \text { D. J. Beyer } \\ 1 & 5365 & \text { G. C. Story } \\ 1 & 5366 & \text { R. G. Miller } \\ 1 & 5371 & \text { D. R. Henson } \\ 1 & 5400 & \text { H. J. Saxton } \\ 1 & 5375 & \text { C. T. Oien } \\ 1 & 5600 & \text { D. B. Hayes } \\ 1 & 5700 & \text { M. J. Eaton } \\ 1 & 5800 & \text { J. L. Wirth }\end{array}$

16613 R. M. Cranwell

18000 J. C. Crawford

18100 M. E. John

208116 R. L. Bierbaum

18400 L. A. Hiles

18455 C. F. Acken

18476 P. G. Heppner

l 9000 G. Yonas

19500 D. S. Miyoshi

19600 J. R. Kelsey

19700 M. M. Newsom

19800 D. J. Rigali

1 8523-2 Central Technical Files

57141 Technical Library

10 7613-2 Document Processing

for DOE/OSTI

17151 Technical Publication 
THIS PAGE INTENTIONALLY LEFT BLANK 

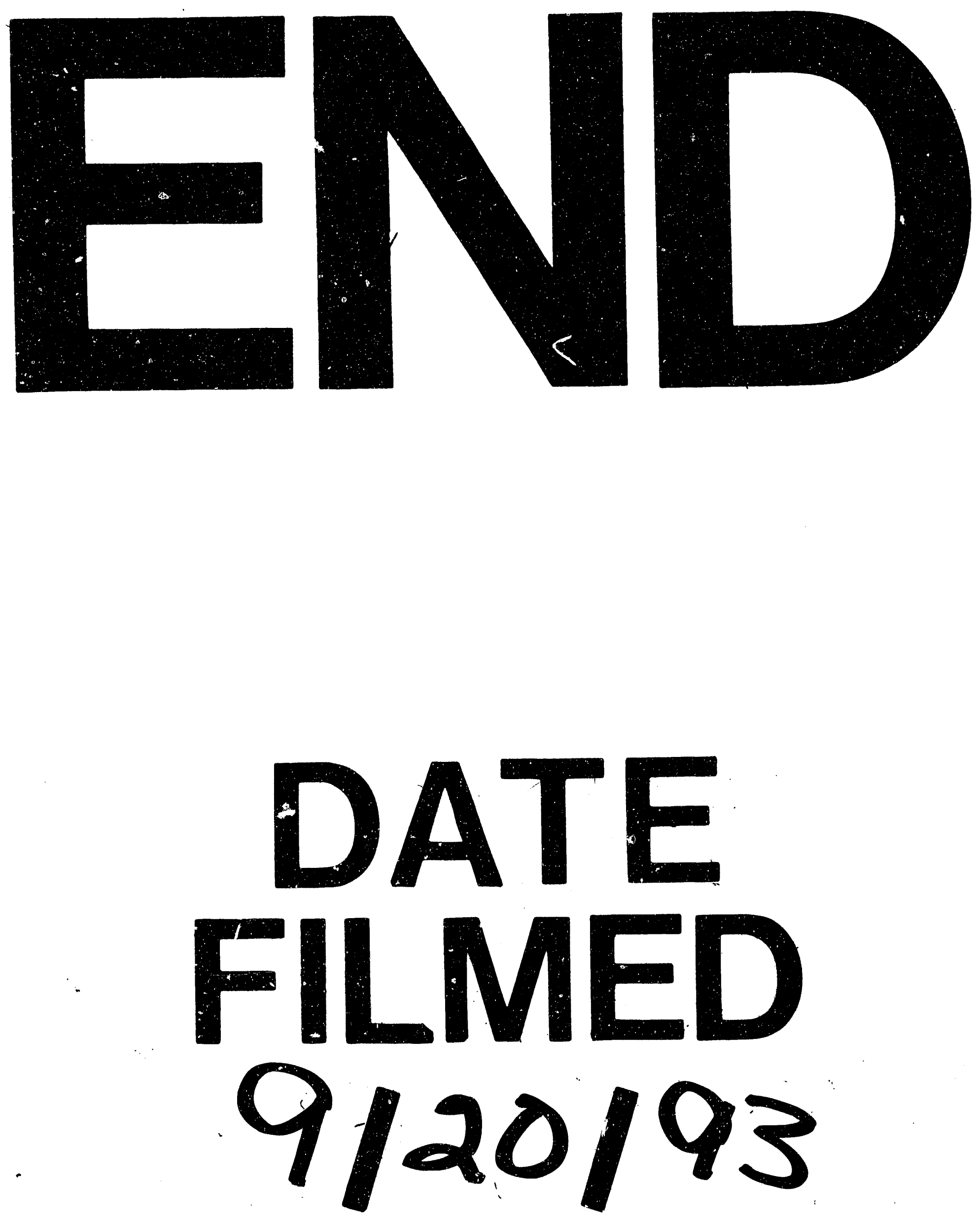

f 
